\title{
Developing a Multi-Product Economic Production Quantity Model to Fuzzy Sense Using of Signed Distance Method
}

\author{
Mohammad Khodashenas ${ }^{1}$, Hamidreza Salmani Mojaveri ${ }^{2 *}$, \\ Fatemeh Mohammadnezhad Chari ${ }^{3}$
}

\begin{abstract}
Today, inventory management issue has become a concern for a lot of organizations and it is the most necessary issues for organizations by production and inventory plan implementing. Among inventory models, models based on economic production quantity are of the most practical models. Each of the economic production quantity is based on set of parameters that are estimated by experts and decision makers. Since uncertainty exists in real world, it is difficult for experts to estimate parameters, accurately. Therefore, in such situation, using economic production quantity under non-integer conditions would be more appropriate than the crisp conditions and also under such conditions organizations have to determine their cumulative production in their supply chain in fuzzy sense. In this paper, a multi-product economic production quantity (EPQ) model, under fuzzy conditions, has been fuzzified and optimized by using signed distance method in order to minimize all costs. a numerical example and sensitivity analysis have also provided to illustrate the practical use of the proposed method.
\end{abstract}

Keywords: Defuzzification, signed distance, fuzzy set, multi-product economic production quantity, inventory.

\section{Introduction}

Continual changes in product requirements to meet customer demand increased uncertainty as less data become available to make long-term predictions. Inventory problems are common in manufacturing, maintenance service and business operations in general. Often uncertainties may be associated with demand, various relevant costs and lead-time. In conventional inventory models, uncertainties are treated as randomness and are handled by probability theory. However, in certain situations, uncertainties are due to fuzziness and in these cases the fuzzy set theory, originally introduced by Zadeh, is applicable. The fuzzy set theory emerged as a useful tool to make less risky decision when very little data is available.

Inventory management is one of the areas where this theory has been applied and gained attention (Guiffrida [12]). Usually researchers consider differrent parameters of an inventory model either as constant or dependent on time or probabilistic in nature for the development of the economic order value,

\footnotetext{
1 Department of Industrial Engineering, South Tehran Branch, Islamic Azad University, Valiasr street, Tehran, Iran Email: Mohi.Khodashenas@gmail.com.

${ }^{2}$ Department of Management and Economic, Science and Research Branch, Islamic Azad University, Shahrak e gharb, Tehran, Iran Email: mazisalmani@yahoo.com.

${ }^{3}$ Department of Industrial Engineering, Payam e Noor University, 15 Khordad street, Sari, Iran

Email: yaldamohammadnejad@yahoo.com.

* Corresponding author
}

which may not follow any probability distribution. In these situations, if these parameters are treated as fuzzy parameters, then it will be more realistic. These types of problems are defuzzified first using suitable fuzzy technique and then the solution quantity model. But in the real life situations, these parameters may have little deviations from the exact procedure can be obtained in the usual manner (Bit et $a l$. [2]).

The first fuzzy inventory model that appeared in the literature is believed to be that of Sommer [22] who applied a fuzzy dynamic programming approach to solve a production-inventory scheduling problem with capacity constraints. Another earlier work is that of Kacpryzk and Stanieski [17] who incurporated the fuzzy set theory into production planning and control problems (Kacpryzk and Stanieski [17]).

The economic order/production quantity (EOQ/EPQ) is the basic model in inventory management that has been of interest of many researchers and practitioners in logistic and inventory systems. Although EOQ/EPQ model provides its user a general understanding of the behavior of an inventory system for a given set of input parameters, it falls short when inventory situations such as quantity discounts and deteriorating or imperfect quality items are considered (Buzacott [6], Flapper et al. [11]).

The aim of this paper is to review the EPQ model under fuzzy sense. In recent years, researchers developed mentioned-model from various aspects. 
For example, Bayindir et al considered EPQ model under variable production rate. In their research, production cost is considered as multi-stage linear function of production and by considering mentioned condition the order economic quantity is calculated (Bayindir et al. [1]). Hou [14] surveyed EPQ model in condition which production process is not perfect process and could have defective products. In his model, quality control costs have been influenced on this model. Similar to this research is conducted by Halim et al. [13], so that they have been used EPQ model for a production system that has defective outputs.

Fuzzy set concept has been widely used to treat the classical inventory model. Park considered fuzzy inventory cost in the economic order quantity model (Park [20]). Chang [8] discussed how to get the economic order quantity, when the quality of demand is uncertain. Hsieh [15], Lee and Yao [18], and Lin and Yao [19], also wrote some articles about fuzzy production model, but all of them have not developed an inventory model with imperfect products (Chang [7]).

Chiu et al. [10] investigated an EPQ model with scrap, network and stochastic machine breakdowns occurring in the production up-time while Chen et al. [9] studied the optimal producer's replenishment policy for an EPQ model with rework, scrap and backorder occurring in backorder replenishment period.

In "harmony search algorithms for inventory management problems" conducted by Taleizadeh [24], application of harmony search (HS) in inventory management problems has been introduced. He implies that four specific inventory problems in certain and uncertain environments are considered: constraint multi-product newsboy problem with fuzzy demand, economic order quantity with advanced payment, bi-objective newsboy problem with fuzzy cost and periodic review problem with stochastic period length and dynamic demands. He has compared the computational performance of the HS method on solving these four optimization problems with other meta-heuristic algorithms such as genetic algorithm (GA), simulated annealing (SA), and particle swarm optimization (PSO) methods, he has concluded that HS method has shown the best performance. Computational results showed that HS, hybrid of HS and fuzzy simulation, and hybrid method of HS, fuzzy simulation and goal programming performed the best, based on objective function values respect to other kind of the algorithms. Other applications of HS in inventory and supply chain management can be extended to consider pricing problems.
In another study by Taleizadeh et al. [23], named "multi-product production quantity model with repair failure and partial backordering", they have studied a production quantity model with random defective items, service level constraint and repair failure. They have determined the optimal cycle length, optimal production quantity and optimal backordered quantity of each product such that the expected total cost (holding, shortage, production, setup, defective items and repair costs) is minimized. They have also provided two numerical examples and sensitivity analysis to illustrate the practical use of the proposed method.

Jinsong et al. [16], from Qingdao University had considered the economic production quantity problem with imperfect items in the fuzzy sense. They have constructed two economic production quantity models with fuzzy defective rate (LR-fuzzy number), in which model 1 is developed when the screening rate is lower than production rate consider, and model 2 is proposed when the screening rate is greater than production rate. And they have employed the signed distance and sample algebraic method to find the optimal production quantity in the fuzzy sense so that the total cost per unit time in the fuzzy sense has a minimum value. Also, numerical examples are given to discuss the effects of fuzziness of defective rates, screening rate and scrap rate on optimal solutions. The results of numerical examples showed that the managers should try them best to reduce the imperfect rate and scrap rate by maintaining the production system in order to cut down the total cost, meanwhile the screening rate should be increased as much as possible to lower the total cost when the manufacturer makes the production plan. Finally they felt the need of more studies on multi-products productions model with imperfect quality as well as considering production models with fuzzy demand and fuzzy random effecttive rate.

Uthayakumar R. and M. Valliathal [25], have presented an Economic Production Quantity model for Weibull deteriorating items over an infinite time horizon under fuzzy environment. They have introduced Fuzziness by allowing the cost components such as setup cost, production cost, holding cost, shortage cost and opportunity cost due to lost sales to certain extent. And they have used Triangular fuzzy numbers to represent the mentioned costs. Optimum policies of the described models under fuzzy costs are derived. They also suggest that the proposed model can be extended in several ways. For instance, the deterministic demand function to stochastic fluctuating demand patterns could be considered. The model could be generalized to allow for quantity discounts, as well as permissible delay in payments. 
Shan Huo Chen et al. [21], have proposed a fuzzy economic production quantity model (FEPQ) with imperfect products that can be sold at a discount price. In their model costs and quantities are expressed as trapezoidal fuzzy numbers. Moreover, they have used function principle to manipulate arithmetical operations, graded mean integration representation method to defuzzify, and Kuhntucker conditions to find the optimal economic production quantity of the fuzzy production inventory model. Their proposed model is applicable when inventory continuously flows or builds up over a period of time after an order has been placed and units are produced and sold simultaneously. The result of the example applying this model was quite feasible and satisfactory, so this model could be applied in more practical and sophisticated cases. For a special case that all variables are set as real numbers, the result will be the same as the traditional non-fuzzy model.

\section{Methods}

\section{Economic Production Quantity (EPQ)}

Inventory management is a common problem to all organization in any sector of the economy. The problems of inventory don't confine themselves to profit-making institutions but also encountered by social and nonprofit institutions. Inventories are common in farms, manufacturing plants, wholesaler warehouses, retailer shops, hospitals, zoos, universities, etc.

The objective of inventory management is to balance conflicting goals. One goal is to keep stock level down to make cash available to other purposes. The purchasing manager may wish to get volume discount s for larger batch order. The production manager may prefer a large row materials inventory to avoid production stoppage due to missing materials. Higher stock of finished goods also provides higher service level. Managing inventory involves efficiently and effectively coordinating both the information and materials flow in the supply chain (Brandimarte and Zotteri [4]).

Inventory management models help to achieve such goals. Due to uncertainty, safety stocks are required. Two types of uncertainty directly impact inventory policy. Demand uncertainty is due to an uncertain rate of sale or demand during lea time. Performance cycle uncertainty involves uncertainty replenishment time variation (Bowersox et al [5]). Uncertainties in demand and cycle length together with leadtimes in production and transportation inevitably create a need for safety stocks. Most organizations can reduce their inventories using inventtory management models.
In the last decades, there have been tremendous efforts by industries to reduce the cost of inventory. The primary concern on inventory management is to reduce the costs of setup and holding. Inventory management has direct relationship with maintaining market share since customers may switch to different vendors due to the shortage.

Economic production quantity (EPQ) model determines the optimal production volume while minimizing the total production-inventory costs. Io other word, EPQ model is a mathematical inventory model that considers finite production rate and EPQ model assumes production rate is higher than the item's demand rate, and machine has no breakdown (Widyadana and Wee [26]).

The traditional Economic Production Quantity that included annual ordering cost plus warehouse rental cost (that is depended on ordering quantity), purchasing cost and maintenance cost is formulated as equation (1):

$K=\frac{D}{Q} C_{0}+\frac{h}{2} Q\left(1-\frac{D}{P}\right)+W \cdot Q+C \cdot D$

To obtain the optimal quantity of $Q$, we should set the equation (1) equal the zero. by solving such relation the optimal quantity is obtained as equation (2):

$Q^{*}=E P Q=\sqrt{\frac{D C_{0}}{\frac{C_{h}}{2}\left(1-\frac{D}{P}\right)+W}}$

To obtain the optimal quantity of $Q_{i}, i=1,2, \ldots, \mathrm{m}$. in multi-product mood, we Derive from equation (4) to $Q_{i}$ and set it equal to zero

$K=\sum_{I=1}^{m}\left[\frac{D_{i}}{Q_{i}} C_{0 i}+\frac{C_{h i}}{2} Q_{i}\left(1-\frac{D_{i}}{P_{i}}\right)+W_{i} Q_{i}+C_{i} D_{i}\right]$

So, we have:

$\frac{\partial K}{\partial Q_{i}}=0 \rightarrow Q^{*}{ }_{i}=\sqrt{\frac{D_{i} C_{0 i}}{\frac{C_{h i}}{2}\left(1-\frac{D_{i}}{P_{i}}\right)+W_{i}}}$

\section{Signed Distance Method}

Definition 1. For each a, $0 \in \mathrm{R}$, a to 0 signed distance is $d \mathrm{o}(a, 0)=a$. if $\mathrm{a}<0$, the distance of a from 0 is $d o(a, 0)=-a$

If $\Omega$ of all the $\tilde{B}$ fuzzy set which are defined on $\mathrm{R}$ and $B(\alpha)=\left[B_{L}(\alpha), B_{U}(\alpha)\right]$, cutting $\alpha$ is $\tilde{B}$ fuzzy set that is existed for each of $\alpha \in[0,1]$ and $B_{L}(\alpha)$ and $B_{U}(\alpha)$ are continuous functions on $\alpha \in[0,1]$, then for each $B \in \Omega$ [4]:

$\tilde{B}=\mathrm{U}_{0 \leq \alpha \leq 1}\left[B_{L}(\alpha)_{\alpha}, B_{U}(\alpha)_{\alpha}\right]$ 
Definition 2. For each $B \in \Omega$ signed distance of $\tilde{B}$ to $\tilde{0}_{1}$ is in the following form:

$$
d\left(\tilde{B}, \tilde{0}_{1}\right)=\left(\frac{1}{2}\right) \int_{0}^{1}\left[B_{L}(\alpha)+B_{U}(\alpha)\right] d \alpha
$$

Feature 1. By Giving The triangular fuzzy number $\tilde{A}=(a, b, c)$, which $\alpha$ is the cut of $\tilde{\mathrm{A}}$, signed distance For each will be as equation (7):

$$
d\left(\tilde{A}, \tilde{0}_{1}\right)=\frac{1}{4}(a+2 b+c)
$$

\section{Multi-Product Economic Production Quantity Model}

In this section, two parameters, including production rate and annual demand are considered in the form of triangular fuzzy numbers. In this condition, annual fuzzy cost function which is represented by $\widetilde{W}\left(Q_{i}\right)$ would be in equation (8) form:

$$
\widetilde{W}\left(Q_{i}\right)=\sum_{l=1}^{m}\left[\frac{\widetilde{D_{l}}}{Q_{i}} C_{0 i}+\frac{C_{h i}}{2} Q_{i}\left(1-\frac{\widetilde{D_{l}}}{\widetilde{P_{l}}}\right)+W_{i} Q_{i}+C_{i} \widetilde{D_{l}}\right]
$$

In this relation we have: $\widetilde{D}_{i}=\left(D_{i}-\Delta_{1 i}^{\prime}, D_{i}, D_{i}+\Delta_{2 i}^{\prime}\right)$ and $\widetilde{P}_{l}=\left(P_{i}-\Delta_{3 i}^{\prime}, P_{i}, P_{i}+\Delta_{4 i}^{\prime}\right)$ which $\Delta_{j i}^{\prime}, j=1, \ldots, 4$ are quantities that have been estimated by informed decision makers and they must apply in the conditions in which $0<\Delta_{1 i}^{\prime}<D_{i} \Delta_{2 i}^{\prime}>00<\Delta_{3 i}^{\prime}<P_{i}$ $\Delta_{4 i}^{\prime}$. For defuzzification of mentioned function in equation (8), signed distance method will be used according to the previous section. Therefore signed distance of $\widetilde{W}$ to $\widetilde{0}$ will be as equation (9) form:

$$
\begin{aligned}
& d\left(\widetilde{W}\left(Q_{i}\right), \widetilde{0}_{1}\right)=\sum_{i=1}^{m}\left[\frac{C_{0 i}}{Q_{i}} d\left(\widetilde{D}_{i}, \widetilde{0}_{1}\right)+\right. \\
& \frac{C_{h i}}{2} Q_{i}\left(1-d\left(\frac{\widetilde{D}_{i}}{\widetilde{P}_{l}}, \widetilde{0}_{1}\right)\right)+W_{i} Q_{i}+C_{i} d\left(\widetilde{D}_{i}, \widetilde{0}_{1}\right)
\end{aligned}
$$

for defuzzification, it is necessary to obtain $d\left(\widetilde{D}_{i}, \tilde{0}_{1}\right)$ and $d\left(\frac{\widetilde{D}_{i}}{\widetilde{P}_{l}}, \widetilde{0}_{1}\right)$ values. Therefore according to equation (7) we will have:

$d\left(\widetilde{D}_{i}, \widetilde{0}_{1}\right)=\frac{1}{4}\left[\left(D_{i}-\Delta_{1 i}^{\prime}\right)+2 D_{i}+\left(D_{i}+\right.\right.$

$\left.\left.\Delta_{2 i}^{\prime}\right)\right]=D_{i}+\frac{1}{4}\left(\Delta_{2 i}^{\prime}-\Delta_{1 i}^{\prime}\right)$

But for calculating $d\left(\frac{\widetilde{D}_{i}}{\widetilde{P}_{l}}, \widetilde{0}_{1}\right)$, first we should obtain end $-a$ left and right points, $\widetilde{D}_{i}$ and $\widetilde{P}_{l}$ cuts which are resulted as equations (11) and (12):

$D_{\mathrm{iL}}(\mathrm{\alpha})=\left(D_{i}-\Delta_{1 i}^{\prime}\right)+\Delta_{1 i}^{\prime} \alpha>0$,

$D_{\mathrm{iU}}(\alpha)=\left(D_{i}+\Delta_{2 i}^{\prime}\right)-\Delta_{2 i}^{\prime} \alpha>0$

$P_{\mathrm{iL}}(\mathrm{\alpha})=\left(P_{i}-\Delta_{3 i}^{\prime}\right)+\Delta_{3 i}^{\prime} \alpha>0$,

$P_{\mathrm{iU}}(\alpha)=\left(P_{i}+\Delta_{4 i}^{\prime}\right)-\Delta_{4 i}^{\prime} \alpha>0$

It should be mentioned that $0<D_{\mathrm{iL}}(\mathrm{\alpha})<D_{\mathrm{iU}}(\mathrm{\alpha})$ $0<P_{\mathrm{iL}}(\mathrm{\alpha})<P_{\mathrm{iU}}(\alpha)$. using equations (11) and (12), will result in a end left and right points of cut, which are as equation (13):

$\left(\frac{\widetilde{D}_{i}}{\widetilde{P}_{l}}\right)_{L}(\alpha)=\frac{D_{i L}(\alpha)}{P_{i U}(\alpha)}=\frac{\left(D_{i}-\Delta_{1 i}^{\prime}\right)+\Delta_{1 i}^{\prime} \alpha}{\left(P_{i}+\Delta_{4 i}^{\prime}\right)-\Delta_{4 i}^{\prime} \alpha}$,
$\left(\frac{\widetilde{D}_{i}}{\widetilde{P}_{l}}\right)_{U}(\alpha)=\frac{D_{i U}(\alpha)}{P_{i L}(\alpha)}=\frac{\left(D_{i}+\Delta_{2 i}^{\prime}\right)-\Delta_{2 i}^{\prime} \alpha}{\left(P_{i}-\Delta_{3 i}^{\prime}\right)+\Delta_{3 i}^{\prime} \alpha}$

So, $\frac{\widetilde{D}_{i}}{\widetilde{P}_{l}}$ signed distance from $\widetilde{0}_{1}$ is as equation (14):

$d\left(\frac{\widetilde{D}_{i}}{\widetilde{P}_{l}}, \tilde{0}_{1}\right)=\frac{1}{2} \int_{0}^{1}\left[\left(\frac{\widetilde{D}_{i}}{\widetilde{P}_{l}}\right)_{L}(\alpha)+\left(\frac{\widetilde{D}_{i}}{\widetilde{P}_{l}}\right)_{U}(\alpha)\right] d \alpha=$

$\frac{1}{2} \int_{0}^{1}\left[\frac{\left(D_{i}-\Delta_{1 i}^{\prime}\right)+\Delta_{1 i}^{\prime} \alpha}{\left(P_{i}+\Delta_{4 i}^{\prime}\right)-\Delta_{4 i}^{\prime} \alpha}+\frac{\left(D_{i}+\Delta_{2 i}^{\prime}\right)-\Delta_{2 i}^{\prime} \alpha}{\left(P_{i}-\Delta_{3 i}^{\prime}\right)+\Delta_{3 i}^{\prime} \alpha}\right] d \alpha=$

$\frac{1}{2}\left[\frac{\left(P_{i} \Delta_{2 i}^{\prime}+D_{i} \Delta_{3 i}^{\prime}\right)}{\Delta_{3 i}^{\prime 2}} \ln \left(\frac{P_{i}}{P_{i}-\Delta_{3 i}^{\prime}}\right)-\frac{\Delta_{2 i}^{\prime}}{\Delta_{3 i}^{\prime}}+\right.$

$\left.\frac{\left(P_{i} \Delta_{1 i}^{\prime}+D_{i} \Delta_{4 i}^{\prime}\right)}{\Delta_{4 i}^{\prime 2}} \ln \left(\frac{P_{i}+\Delta_{4 i}^{\prime}}{P_{i}}\right)-\frac{\Delta_{1 i}^{\prime}}{\Delta_{4 i}^{\prime}}\right]$

Now, by obtaining above relations, diffuzzificated total cost function of inventory is changed as bellow:

$w^{*}\left(Q_{i}\right)=\sum_{i=1}^{m}\left[\frac{C_{0 i}}{Q_{i}}\left(D_{i}+\frac{1}{4}\left(\Delta_{2 i}^{\prime}-\Delta_{1 i}^{\prime}\right)\right)\right.$

$+\frac{C_{h i}}{2} Q_{i}\left(1-\frac{1}{2}\left[\frac{\left(P_{i} \Delta_{2 i}^{\prime}+D_{i} \Delta_{3 i}^{\prime}\right)}{\Delta_{3 i}^{\prime 2}} \ln \left(\frac{P_{i}}{P_{i}-\Delta_{3 i}^{\prime}}\right)-\frac{\Delta_{2 i}^{\prime}}{\Delta_{3 i}^{\prime}}+\right.\right.$

$\left.\frac{\left(P_{i} \Delta_{1 i}^{\prime}+D_{i} \Delta_{4 i}^{\prime}\right)}{\Delta_{4 i}^{\prime 2}} \ln \left(\frac{P_{i}+\Delta_{4 i}^{\prime}}{P_{i}}\right)-\frac{\Delta_{1 i}^{\prime}}{\Delta_{4 i}^{\prime}}\right)$

$\left.+W_{i} Q_{i}+C_{i}\left(D_{i}+\frac{1}{4}\left(\Delta_{2 i}^{\prime}-\Delta_{1 i}^{\prime}\right)\right)\right]$

In order to determine the economic production quantity of it, product of total cost function is $\left(w^{*}\left(Q_{i}\right)\right)$, differentiated relating to $Q_{i}$, derived than setting equal to zero. So, economic production quantity (EPQ) will be as equation (16) form:

$Q_{i}^{*}=$

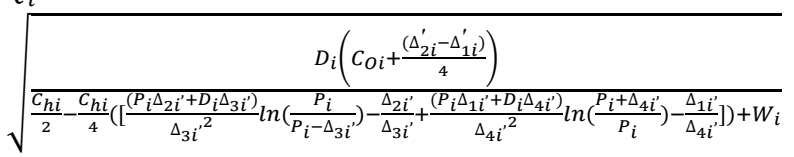

\section{Results and Discussions} Comparison and Sensitivity Analysis of
Model's Parameters in Fuzzy and Crisp Case

In the following section, we explain some examples provided for comparison between the result of proposed model and those of crisp model in addition to sensitivity analysis. Since the proposed model is multi item, this comparison can be applied for all items in an inventory system, but we perform the operation for one item. Consider the item A is a product in a company and inventory control department want to order this product for company and obtained data are given by: 
$D_{A}=11056$ unit/year, $C_{o A}=5200 \$ /$ cycle,$C_{h A}=$ $2 \$ /$ unit/year ${ }_{p A}=0.06 \$ /$ unit,$W_{A}=500 \$ /$ year $C_{A}=0.33 \$ /$ unit/year. Furthermore assume that expert's viewpoint about these values are respectively set as: $\Delta_{1 \mathrm{~A}}=280, \Delta_{2 \mathrm{~A}}=320$ and $\Delta_{3 \mathrm{~A}}=0.05, \Delta_{4 \mathrm{~A}}=$ 0.2 and $\Delta_{5 \mathrm{~A}}=0.01, \Delta_{6 \mathrm{~A}}=0.02$ and $\Delta_{7 \mathrm{~A}}=0.5, \Delta_{8 \mathrm{~A}}=$ 1.25 and $\Delta_{9 \mathrm{~A}}=200, \Delta_{10 \mathrm{~A}} 500$ and $\Delta_{11 \mathrm{~A}}=0.12, \Delta_{12 \mathrm{~A}}=$ 0.35

First of all we should check the condition impose to formula (15) because if this condition isn't true, we can't use it to determine optimal order quantity. With given data, equation (16) is satisfied for all five products therefore we can estimate optimal order quantity with the proposed relation in this article. In Table 3 the optimal order quantity $\left(Q_{A}^{*}\right)$ and optimal total cost in each year $\left(T C_{i}^{*}\right)$ are calculated in both fuzzy and crisp case and variation between them is measured by $\operatorname{Rel} Q=\left[\left(Q_{A}^{*}-Q_{A C}^{*}\right) / Q_{A C}^{*}\right] \times$ $100 \%$ and $\operatorname{Rel} T C=\left[\left(T C_{A}^{*}-T C_{A C}^{*}\right) / T C_{A C}^{*}\right] \times 100 \%$. The results in Table 1 indicate that there is an increase with $0.21 \%$ in $Q_{A}^{*}$ and $0.158 \%$ in $T C_{A}^{*}$ in fuzzy case rather than crisp case.

Now in order to perform sensitivity analysis, we consider two parameters of model in each table. In table 3 two parameters, annual demand $D_{A}$, which is considered as crisp, and order cost $C_{O A}$, which is one the fuzzy parameters of proposed model, are considered. If we decrease $25 \%$ in $D_{A}$ and $C_{O A}$ the result shows that there is a respectively decrease of $13.3 \%$ and $13.38 \%$ with $D_{A}$ and $C_{O A}$. In the other hand if we increase $25 \%$ in $D_{A}$ and $C_{O A}$ the result show that there is an respectively increase of $11.79 \%$ and $11.79 \%$ with $D_{A}$ and $C_{O A}$. Hence variation in these two parameters is almost identical. It means that if we increase the mentioned values, the optimal order quantity will increase and inversely if we decrease these values, the optimal quantity will decrease. The same result could be deducted for optimal total cost (see Table 2).

Table 1. Comparison between fuzzy and crisp case

\begin{tabular}{lrr}
\hline & $Q_{A}^{*}$ & \multicolumn{1}{c}{$w^{*}\left(Q_{i}\right)$} \\
\hline Crisp & 338.757 & 343077.8905 \\
Fuzzy & 339.450 & 343622.1412 \\
Increase (\%) & 0.210 & 0.1580 \\
\hline
\end{tabular}

Table 2. Sensitivity analysis of two parameters

\begin{tabular}{rrrrrr}
\hline$D_{A}$ & $Q_{A}^{*}$ & $w^{*}\left(Q_{i}\right)$ & \multicolumn{1}{c}{$C_{0 A}$} & \multicolumn{1}{c}{$Q_{A}^{*}$} & $w^{*}\left(Q_{i}\right)$ \\
\hline-25 & -13.30 & -13.54 & -25 & -13.38 & -13.20 \\
+25 & 11.79 & 11.96 & +25 & 11.79 & 11.63 \\
\hline
\end{tabular}

Table 3. Sensitivity analysis of two parameters

\begin{tabular}{rrrrrr}
\hline \multicolumn{1}{c}{$P_{A}$} & $Q_{A}^{*}$ & $w^{*}\left(Q_{i}\right)$ & \multicolumn{1}{c}{$C_{0 A}$} & \multicolumn{1}{c}{$Q_{A}^{*}$} & $w^{*}\left(Q_{i}\right)$ \\
\hline-25 & 0.00008 & $-2.3 \times 10^{7}$ & -25 & 15.49 & -13.23 \\
+25 & 0.00006 & 0.054 & +25 & -10.56 & 11.66 \\
\hline
\end{tabular}

\section{Conclusion}

We considered a multi-product EPQ model under fuzzy sense. For first, the prominent parameters in the EPQ model namely production and demand rate surveyed fuzzy sets using singed distance method. In the real world, the mentioned parameters cannot estimate under deterministic environments because the parameters quantities will be inaccurate in crisp senses. The model developed in this paper could also be examined by applying different membership functions, different fuzzification and defuzzification methods, and the obtained result could be compared to with those of this paper. Moreover and to get further insights, the parameters of the employed membership functions could be tuned by applying some algorithms, such as the genetic algorithms (GA). It would be interesting to see for which level of fuzziness the optimal quantities of fuzzy models can be reduced to the classical model. Another possible and interesting future work may include extending the model developed here into a fuzzy stochastic environment. Also, the approach used in this paper may be applied to other inventory models that have not been investigated in a fuzzy context.

Furthermore, future researches may extend the fuzzy multi-product EPQ model using different solution methods for example metric distance, Graded Mean Integrations Representation(GMIR) and etc. also, the EPQ model can mixture methods for example, Material Requirement Planning (MRP), supplier selection problem, production planning and etc.

\section{References}

1. Bayindir, Z. P., Birbil, S. I., and Frenk, J. B. G., A Deterministic Inventory Production Model with General Inventory Cost Rate Function and Piecewise Linear Concave Production Costs, European Journal of Operational Research, 179(1), 2007, pp. 114-123.

2. Bit, A. K., Biswal, M. P., and Alam, S. S., Fuzzy Programming Approach to Multi-criteria Decision Making Transformation Problem, Fuzzy Sets and Systems, 50, 1992, pp. 135-142.

3. Björk, K. M., An Analitical Solution to a Fuzzy Economic Order Quantity Problem, International Journal of Approximate Reasoning, 50, 2009, pp.458-493.

4. Brandimarte P., and Zotteri, G., Introduction to Distribution Logistics, First ed., John Wiley \& Sons, New Jersey, USA, 2007.

5. Bowersox, D. J, Closs, D. J., and Cooper, M. B., Supply Chain Logistics Management, Second ed., MC Graw. Hill, New York, USA, 2007.

6. Buzacott, J. A., The Structure of Manufacturing Systems: Insights on the Impact of Variability, International Journal of Flexible Manufacturing Systems,11(2), 1999, pp. 702-707. 
7. Chang, S. C., Fuzzy Production Inventory for Fuzzy Product Quantity with Triangular Fuzzy Number, Fuzzy Sets and Systems, 107, 1999, pp. 37-57.

8. Chang, H-C., An Application of Fuzzy Sets Theory to the EOQ Model with Imperfect Quality Items, Computers and Operations Research, 31, 2004, pp.2079-2092.

9. Chen, K. K, Y-S. P.Chiu and Ting, C-K., Producer's Replenishment Policy for an EPQ Model with Rework and Machine Failure Taking Place in Backorder Reloading Time, WSEAS Transaction on Mathematic, 9, 2010, pp.223-233.

10. Chiu, S. W., Production Run Time Problem with Machine Breakdowns under AR Control Policy and Rework, Journal of Scientific and Industrial Research, 66, 2007, pp.979-988.

11. Flapper S. D. P., Fransoo, J. C., Broekmeulen, R. A. C. M., and Inderfurth, K., Planning and Control of Rework in the Process Industries: A Review, Production Planning and Control, 13(1), 2002, pp. 26-34.

12. Guiffrida, A. L., Fuzzy Inventory Models, in: M. Y. Jaber (Ed.), Inventory Management: Nonclassical Views, CRC Press, FL, Boca Raton, 2009, pp. 173-190.

13. Halim, K.A., Giri, B. C., and Chaudhuri, K. S., Fuzzy EPQ Model for an Imperfect Production System, International Journal of System Science, 40(1), 2009, pp. 45-52.

14. Hou, K. L., An EPQ Model with Setup Costs and Process Quality as Function of Capital Expenditure, Applied Mathematical Modeling, 31(1), 2007, pp. 10-17.

15. Hsieh, C. H., Optimization of Fuzzy Production Inventory Models, Information Science, 146, 2002, pp.29-40.

16. Jinsong Ho, Ruqian Xu, and Caiyun Guo, Fuzzy Economic Production Quantity Models for Items with Imperfect Quality, International Journal of Information and Management Sciences, 22, 2011, pp. 43-58.

17. Kacpryzk, J., and Stanieski, P., Long Term Inventor Policy-making through Fuzzy Decision Making Models, Fuzzy Sets and Systems, 8(2), 1982, pp. 117-132.
18. Lee, H. M., and Yao, J. S., Economic Production Quantity for Fuzzy Demand Quantity and Fuzzy Production Quantity, European Journal of Operational Research, 109, 1998, pp.203-211.

19. Lin, D. C., and Yao, J. S., Fuzzy Economic Production for Production Inventory, Fuzzy Set and Systems, 111, 2000, pp.465-495.

20. Park, K. S., Fuzzy Set Theoretic Interpretation of Economic Order Quantity, IEEE Transactions on Systems, Man, and Cybernetics, SMC-17, 1987, pp. 1082-1084.

21. Shan Huo Chen, Chien-Chung, Wang and Shu Man Chang, Fuzzy Economic Production Quantity Model for Items with Imperfect Quality, International Journal of Innovative Computing, Information and Control, 3(1), 2007, pp. 85-95, Feburary 2007.

22. Sommer, G., Fuzzy Inventory Scheduling, in: Lasker, G, ed. Applied Systems and Cybernetics, New York: Pergamon Press, pp.3052-3060, 1981.

23. Taleizadeh, A. A, Wee, H.M., and Sadjadi, S. J., Multi-product Production Quantity Model with Repair Failure and Partial Backordering, Journal of Computers and Engineering, 59, 2010, pp. 45-54.

24. Taleizadeh, A. A., Harmony Search Algorithms for Inventory Management Problems, African Journal of Business Management, 6(36), 2012, pp. 9864-9873, 12 September, 2012, available online at http://www.academicjournal.org/ AJBM.

25. Uthayakumar, R., and Valliathal, M., Fuzzy Economic Production Quantity Model for Weibull Deteriorating Items with Ramp Type of Demand, International Journal of Strategic Decision Sciences (IJSDS), Gandhigram Rural University, India,Chikkaiah Naicker College, India, 2011. Source title: http://www.igi-global. com/article/fuzzy-economic-production-quantitymodel/58318.

26. Widyadana, G. A. and Wee, H. M., Economic Production Quantity (EPQ) Deteriorating Inventory Model with Machine Breakdown and Stochastic Repair Time, Proceeding of the IEEE IEEM, 2009. 